\title{
OCULAR MANIFESTATION AND LONG STANDING VISUAL IMPAIRMENT FOLLOWING VENOMOUS SNAKE BITE
}

Somnath Das ${ }^{1}$, Sandip Samaddar², Subhasish Jana ${ }^{3}$

\section{HOW TO CITE THIS ARTICLE:}

Somnath Das, Sandip Samaddar, Subhasish Jana. "Ocular Manifestation and Long Standing Visual Impairment Following Venomous Snake Bite". Journal of Evolution of Medical and Dental Sciences 2015; Vol. 4, Issue 46, June 08; Page: 7919-7923, DOI: 10.14260/jemds/2015/1153

ABSTRACT: OBJECTIVE: Snake bite is an environmental hazard associated with significant ocular morbidity and some have sight threatening complications. Objective of this study was to determine the ocular manifestations and long standing visual impairment following snake bite and to acquaint the ophthalmologists and related health professionals about the sight threatening ocular complications related to snake bite. METHODS: Prospective data was collected from the Dept. of Internal Medicine, Burdwan Medical College, a rural based tertiary care hospital in eastern India. All snake bite patients admitted in the Department of Internal Medicine were examined and all patients with ocular manifestations were included in the study. RESULTS: Out of 245 cases of snake bite, $51(27.27 \%)$ cases of venomous snake bite with ocular findings were included in this study. Thirty three (64.71\%) out of 51 were vasculotoxic and 18(35.29\%) were neurotoxic in nature. Commonest ocular manifestation of neurotoxic bite was ptosis, followed by diplopia, ophthalmoplegia and optic neuritis. In vasculotoxic snake bites retinal and vitreous hemorrhage (36.36\%) was most common followed by subconjunctival hemorrhage and chemosis $(27.28 \%)$, lid oedema (18.18\%), hyphaema $(12.12 \%)$ and anterior uveitis (6.06\%). Causes of long standing visual impairment were retinal hemorrhage in one patient and vitreous hemorrhage in two patients. CONCLUSIONS: Ocular morbidity following snake bite were more common among young males. Majority of long standing visual impairment were associated with vasculotoxic snake bite and required long term follow-up.

KEYWORDS: snake bite, ocular manifestations, visual impairment.

INTRODUCTION: Snakebite is an environmental hazard associated with significant morbidity and mortality. A large number of victims survive with permanent physical and psychological sequelae. Despite the scale of its effects on populations, snakebite has not received the attention it deserves from

National and international health authorities, and has been appropriately categorized as a 'neglected tropical disease'. ${ }^{1}$ In India, an estimated 200,000 persons per year fall prey to snakebite, with an estimated fatality rate of 35,000-50,000 per year. ${ }^{2}$ The incidence of envenomation is particularly high in tropical regions where snakes are abundant and human activities like field work and sleeping outdoors increase the risk of man-snake encounters. ${ }^{3}$ South Asia is the world's most heavily affected region, due to high population density, widespread agricultural activities, numerous snake species and lack of functional snake bite control programs. ${ }^{4}$

Ocular complications following snake bite are usually rare. Isolated case reports describing ocular manifestations of snake bite have been reported in literature. These include ophthalmoplegia, uveitis, glaucoma, central retinal artery occlusion, macular infraction, optic neuritis, vitreous hemorrhage, penetrating eye injury, globe necrosis cortical infarction and endogenous endophthalmitis. ${ }^{5-11}$ 
However, no attempt has been made to quantify the burden of ocular manifestations of venomous snake bites and no data regarding long term visual morbidity following poisonous snakebites has been reported.

As such the present study was planned to document the ocular manifestations and causes of long standing visual impairment following venomous snake bite.

MATERIALS AND METHODS: This was a prospective observational study, conducted between May 2012 to October 2012 at Burdwan Medical College and Hospital, a tertiary care Centre in rural setup in eastern India. The study protocol was approved by Institutional Ethics Committee. All snake bite patients admitted in the Dept. of Internal Medicine, of this hospital were examined and only cases of envenomation with ocular manifestations were included in our study. Venomous bite was defined by the presence of signs and symptoms of local and/or systemic toxicity. Local toxicity was defined by the presence of a local reaction in the form of swelling, bleeding from fang marks, cellulitis, or necrosis. Clinical features such as bleeding from mucocutaneous sites, systemic bleeding, intravascular haemolysis, or a deranged laboratory coagulation profile anytime during hospital stay indicated a vasculotoxic bite. Neurotoxic bite was considered in case of paresthesias, taste and smell abnormalities, ptosis, cranial nerve palsy, general flaccidity, or respiratory paralysis. Polyvalent anti snake venom (ASV) and other supportive therapy was instituted as per hospital protocol.

RESULTS: A total 245 cases of snake bite patients were admitted in the study period, from May 2012October 2012. One hundred eighty seven cases (76.33\%) were poisonous. Fifty eight (23.67\%) were non-poisonous snake bites and hence excluded from the study. Fifty one out of 187 bites (27.27\%) had ocular findings. The median age was 24 years (Range 18 -38 years). 32 subjects $(62.74 \%$ ) were male and 19 subjects $(37.26 \%)$ were female. Thirty eight $(74.5 \%)$ of bites were in the lower third of leg and feet. Distribution of sites of snake bite is shown in Fig. 1 Thirty three out of 51(64.71\%) cases, were vasculotoxic and the rest neurotoxic. The common ocular manifestation of neurotoxic bites was ptosis, poor vision, ophthalmoplegia and optic neuritis in decreasing order. (Table 1). Retinal and vitreous hemorrhage, subconjunctival hemorrhage and chemosis, lid oedema, hyphaema and anterior uveitis were seen in vasculotoxic snake bites (Table 2). Three patients had long standing visual impairment. Causes of long standing visual impairment were retinal hemorrhage in one case and vitreous hemorrhage in two cases.

DISCUSSION: Present study highlights the burden of ocular manifestations of snake bite and its long standing visual impairment in a defined group of rural population. Out of 245 cases of snake bite that were admitted in the hospital during the study period, 51 cases $(27.27 \%)$ had ocular manifestations and were analyzed.

The venomous snakes most often encountered in India are the Indian spectacled cobra (Najanaja), common krait (B. caeruleus), Russell's viper (Daboia russelli) and the Saw scaled viper (Echis carinatus). Snake venom is a complex mixture of several enzymes and proteins, toxic polypeptides, and inorganic components. It contains numerous toxins, and their combined action has a more potent effect than that of their individual effects. In general, venoms are described as either neurotoxic or hematotoxic.12 Cobra and krait envenomation is typically neurotoxic, whereas envenomation by Viperidae species shows characteristic vasculotoxic and haematotoxic features. Patil VC et $\mathrm{al}^{4}$ reported that $85.43 \%$ cases in their series were vasculotoxic and $14.56 \%$ were 


\section{ORIGINAL ARTICLE}

neurotoxic. Males were more commonly affected than females. Brunda $\mathrm{G}$ et al, ${ }^{2}$ reported $76 \%$ cases of snake bite to be males. We also found a male preponderance and higher incidence of vasculotoxic bites in our series. As significant number of snakebite victims were seen in the economically productive age group. Therefore, the economic impact of ocular morbidities as a sequelae of snake bite are likely to be high.

Ocular manifestations were more common in vasculotoxic snake bite in our series. Retinal and vitreous haemorrhage were noted to be the commonest. Vasculotoxic snake venom has several biologically active procoagulant enzymes that lead to rapid activation of factors $\mathrm{V}, \mathrm{X}$ amongst other steps in the clotting cascade. This leads to formation of fibrin cross links, which are promptly lysed by the fibrinolytic system.13 Eventually this leads to disseminated Intravascular coagulation and coagulopathy that can cause sub-conjunctival and intraocular haemorrhage. Anterior uveitis following snake bite has been reported uncommonly. We report 2 cases of uveitis in our series. One case was acute, noted at presentation and the other case manifested 4 days post admission to hospital. The cause of uveitis is unclear. Acute anterior uveitis may be due to the direct toxic effect of the snake venom. Late onset uveitis following venomous bite is probably due to serum sickness like response to horse ASV serum. ${ }^{14}$

In the present study common ocular manifestations of neurotoxic snake bites were ptosis followed by diplopia, ophthalmoplegia and optic neuritis, in order of decreasing incidence. Seneviratne $U$ et al ${ }^{15}$ in their study of 56 patients with neurological manifestations of snake bite, reported that ptosis and ophthalmoplegia were the commonest neurological manifestations Singh J et al, ${ }^{3}$ in an analysis of 33 venomous snake bites in a military operational area of north India reported 21 patients to be neurotoxic in nature. Ptosis, diplopia and blurred vision were common finding Neuromuscular paralysis occurs as a result of blockade of neuromuscular transmission. The neurotoxins have phospholipase A2 activity and hydrolyze phosphoglycerides thereby producing neuromuscular blockade by inhibiting the release of acetylcholine from the presynaptic membrane.16,17 The effects of snake venom neurotoxin always appears first in the muscles supplied by the cranial nerves, usually the extra ocular and levator muscles. The extra ocular muscles are especially susceptible to neuromuscular blockage because the ratio of nerve fibers to extra-ocular muscle fibers (1:6 to $1: 12$ ) is high compared to that seen in the large proximal limb muscles (1:2000). ${ }^{18}$ Therefore, a small amount of neurotoxin is capable of producing an increased effect on the extra ocular and levator muscles. This explains our study finding of ptosis and ophthalmoplegia to be the commonest features of neurotoxic envenomation.

Out of 51 cases that had ocular manifestations in our study only 3 cases suffered significant visual impairment at the end of six month follow up. One patient had persistent uniocular vitreous hemorrhage, the second patient had bilateral late onset severe uveitis along with vitreous hemorrhage and the third patient suffered from optic neuritis sequelae along with hemorrhage on macula. The first patient refused any intervention in his eye.

The study has limitations. The true burden of snakebites may not be reflected in a hospital data, because in developing countries, snakebite victims may preferentially attend traditional healers and may not seek treatment at hospital. Besides, the study duration is short and follow up was only six months.

To conclude, our study is first of it's kind to report a spectrum of ocular manifestations in venomous snake bites in a defined rural population. There is a need to develop health intervention strategies, adapted for the particular needs of every country, to achieve more rapid access to 
antivenom in health facilities. Early treatment and close monitoring will help to reduce ocular morbidity. Public health education aimed at increasing the awareness about the hazards of snake bite, early hospital referral and effective treatment will undoubtedly reduce the global burden of human suffering inflicted by this neglected tropical disease.

\section{REFERENCES:}

1. Warrell DA, Gutiérrez JM, Calvete JJ, Williams D. New approaches \& technologies of venomics to meet the challenge of human envenoming by snakebites in India. Indian J Med Res. 2013; 138: 38-59.

2. Brunda G, Sashidhar RB. Epidemiological profile of snake bite cases from Andhra Pradesh using immunoanalytical approach. Indian J Med Res. 2007; 125: 661-8.

3. Singh J, Bhoi S, Gupta V, Goel A. Clinical profile of venomous snake bites in north Indian Military Hospital. J Emerg Trauma Shock. 2008; 1: 78-80.

4. Patil VC, Patil HV, Patil A, Agrawal V. Clinical Profile and outcome of envenomous snake-bite at tertiary care centre in western Maharastra. Int. J Med. Public health 2011; 4: 28-38.

5. Bhalla A, Jain AP, Banait S, Jajoo UN, Kalantri SP. Central retinal artery occlusion: an unusual complication of snakebite. J venom Anim Toxins incl Trop Dis. 2004; 10: 311-4.

6. Takeshita T, Yamada K, Hanada M, Oda-Ueda N. Extraocular muscle paresis caused by snakebite. Kobe J Med Sci. 2003; 49: 11-5.

7. Menon V, Tandon R, Sharma T, Gupta A. Optic neuritis following snake bite. Indian J Ophthalmol 1997; 45: 236-7.

8. Singh J, Singh P, Singh R, Vig VK. Macular infarction following viperine snake bite. Arch Ophthalmol 2007; 125: 1430-1.

9. Hayreh SS. Transient central retinal artery occlusion following viperine snake bite. Arch Ophthalmol 2008; 126: 870-1.

10. Rao BM. A case of bilateral vitreous haemorrhage following snake bite. Indian J Ophthalmol 1977; 25: 1-2.

11. Iqbal M, Khan BS, Ahmad I. Endogenous Endophthalmitis Associated With Snake Bite. Pak J Ophthalmol 2009; 25: 114-16.

12. Law AD, Agrawal AK, Bhalla A. Indian common krait envenomation presenting as coma and hypertension: A case report and literature review. Emerg Trauma Shock. 2014; 7: 126-8.

13. Tungpakorn N. Unusual visual loss after snakebite. J. Venom. Toxins incl. Trop. Dis. 2010; 16: $519-523$.

14. Nayak SG, Satish R, Nityanandam S, Thomas RK. Uveitis following anti-snake venom therapy. J. Venom. Toxins incl. Trop. Dis. 2007; 13: 13.

15. Seneviratne U, Dissanayake S. Neurological manifestations of snake bite in Sri Lanka. Journal of Postgraduate Medicine 2002; 48: 275-8. 0-34.

16. Bawaskar HS, Bawaskar PH. Envenoming by the common krait (Bungarusbcaeruleus) and asian cobra (Naja naja): Clinical manifestations and their management in a rural setting. Wilderness Environ Med 2004; 15: 257-66.

17. Lewis RL, Gutmann L. Snake venoms and the neuromuscular junction. Semin Neurol. 2004; 24: 175-9.

18. Kim HD, Jung MS, Kim SY. Exotropia caused by pit viper snakebite. J AAPOS. 2009; 13(4): 424-5. 
ORIGINAL ARTICLE

\begin{tabular}{|c|c|c|}
\hline Ocular Findings & No. of cases & Percentage of cases \\
\hline Ptosis & 7 & $38.9 \%$ \\
\hline Poor vision & 4 & $22.22 \%$ \\
\hline Diplopia & 3 & $16.66 \%$ \\
\hline Ophthalmoplegia & 2 & $11.11 \%$ \\
\hline Optic neuritis & 2 & $11.11 \%$ \\
\hline
\end{tabular}

Table 1: Ocular manifestation of neurotoxic snake bite $(n=18)$

\begin{tabular}{|c|c|c|}
\hline Ocular Findings & No. of cases & Percentage of cases \\
\hline Retinal \& vitreous hemorrhage & 12 & $36.36 \%$ \\
\hline Subconjunctival hemorrhage $\&$ chemosis & 9 & $27.27 \%$ \\
\hline Lid oedema & 6 & $18.2 \%$ \\
\hline Hyphema & 4 & $12.12 \%$ \\
\hline Anterior Uveitis & 2 & $6.05 \%$ \\
\hline
\end{tabular}

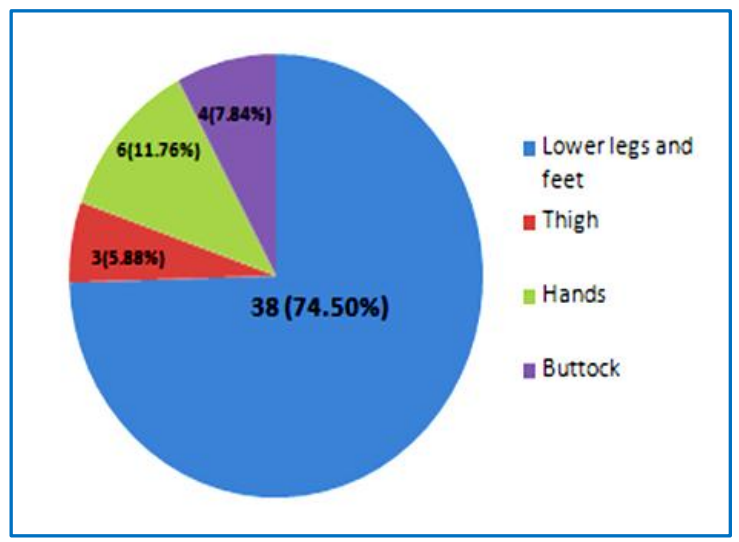

\section{Fig. 1: Pie diagram showing distribution of site of bites $(n=51)$}

\section{AUTHORS:}

1. Somnath Das

2. Sandip Samaddar

3. Subhasish Jana

\section{PARTICULARS OF CONTRIBUTORS:}

1. Associate Professor, Department of RIO, Kolkata.

2. Assistant Professor, Department of RIO, Kolkata.

FINANCIAL OR OTHER

COMPETING INTERESTS: None
3. Post Graduate Tutor, Department of Ophthalmology, Burdwan Medical College.

\section{NAME ADDRESS EMAIL ID OF THE} CORRESPONDING AUTHOR:

Dr. Sandip Samaddar,

25, Sarat Chandra Road, Kolkata-700008.

E-mail: drsandipsamaddar@gmail.com

Date of Submission: 18/05/2015. Date of Peer Review: 19/05/2015. Date of Acceptance: 01/06/2015. Date of Publishing: 05/06/2015. 